[14] Meyer, R., Fleming, C., Dominguez-Ortega, G., Lindley, K., Michaelis, L., Thapar, N. et. al. (2013). Manifestations of food protein induced gastrointestinal allergies presenting to a single tertiary paediatric gastroenterology unit. World Allergy Organization Journal, 6, 13. doi: http://doi.org/10.1186/1939-4551-6-13

[15] Global strategy for asthma management and prevention (2015). National institutes of health. National Heart, lung and Blood Institute. Available at: http://www.ginasthma.org

[16] Scaparrotta, A., Di Pillo, S., Attanasi, M., Rapino, D., Cingolani, A., Consilvio, N. P. et. al. (2012). Montelukast versus inhaled corticosteroids in the management of pediatric mild persistent asthma. Multidisciplinary Respiratory Medicine, 7 (1), 1-9. doi: http://doi.org/10.1186/2049-6958-7-13

[17] Buck, M. (2015). Montelukast: a review of recent studies in pediatric asthma and allergic rhinitis. Pediatric Pharmacology, 21 (4). Available at: http://www.medscape.com/viewarticle/845468

[18] Pei, A. Y. S., Chan, H. H. L., Leung, T. F. (2001). Montelukast in the treatment of children with moderate-to-severe atopic dermatitis: A pilot study. Pediatric Allergy and Immunology, 12 (3), 154-158. doi: http://doi.org/10.1034/j.1399-3038.2001.012003154.x

[19] Oh, J., Lee, H. (2004). Study of urinary leukotriene E4 and serum eosinophil cationic protein in children with atopic dermatitis and their correlation with disease activity. Journal of Allergy and Clinical Immunology, 113 (2), S56. doi: http:// doi.org/10.1016/j.jaci.2003.12.165

[20] Gupta, S. K., Peters-Golden, M., Fitzgerald, J. F., Croffie, J. M., Pfefferkorn, M. D., Molleston, J. P. et. al. (2006). Cysteinyl Leukotriene Levels in Esophageal Mucosal Biopsies of Children with Eosinophilic Inflammation: Are They All the Same? The American Journal of Gastroenterology, 101 (5), 1125-1128. doi: http://doi.org/10.1111/j.1572-0241.2006.00557.x

\title{
PECULIARITIES OF TLR-2 (ARG753GLN) AND TLR-4 (ASP299GLY) POLYMORPHISM PREVALENCE IN PATIENTS WITH ACUTE BRUCELLEIS AND CARDIOVASCULAR SYSTEM DISEASES
}

\author{
Elchin Huseynov Mammad oglu \\ Department of Infectious Diseases \\ Azerbaijan Medical University \\ 23 Bakikhanov str., Baku, Azerbaijan, AZ1022 \\ elchinhuseynov@mail.ru
}

\begin{abstract}
Currently, there are single data on the relationship between TLR-2 polymorphisms (Arg753Gln) and TLR-4 (Asp299Gly) polymorphisms and susceptibility to brucellosis. Therefore, the aim of the study was to determine the frequency of TLR-2 (Arg753Gln) and TLR-4 (Asp299Gly) polymorphisms in patients with acute brucellosis with cardiovascular lesions in the Republic of Azerbaijan.

Materials and methods: 178 patients with a brucellosis clinic were examined. According to the criteria for inclusion in the study, only 120 people fully met all the criteria, which made up the main group. The control group consisted of 30 healthy individuals. TLR-2 (Arg753Gln) and TLR-4 (Asp299Gly) polymorphisms were also determined for all patients in both groups. In order to assess the state of the cardiovascular system, an electrocardiogram was recorded, blood pressure was measured, and an ultrasound scan of the heart was performed for all patients.

Results: it was found that 93 patients $(77.50 \pm 3.13 \%)$ with acute brucellosis had some or other signs of impairment in the work of the cardiovascular system, identified clinically or as a result of functional examination. Among carriers of the Asp/Gly genotype of the TLR-4 gene, an increased risk of brucellosis with CVS diseases was determined $\left(\chi^{2}=30.19 ; \mathrm{p}<0.0001 ; \mathrm{OR}=24.29 ; 95 \% \mathrm{CI}[5.45-\right.$ 108.37]), while the carriage of the homozygous genotype Asp/Asp, by contrast, had a protective effect on the development of brucellosis $(\mathrm{OR}=0.06,95 \% \mathrm{CI}[0.02-0.20])$. Among the carriers of the Arg/Gln genotype and the Gln/Gln genotype of the TLR-2 gene, a significantly increased risk of brucellosis with CVS diseases was determined $\left(\chi^{2}=5.68 ; \mathrm{p}=0.02 ; \mathrm{OR}=3.10 ; 95 \% \mathrm{CI}[0.99-9.67]\right)$ and $(\mathrm{OR}=2.48$;
\end{abstract}


$95 \%$ CI [0.53-11.61]), respectively. While the carriage of the homozygous Arg/Arg genotype, by contrast, was rarely seen in patients with brucellosis (OR=0.28, $95 \% \mathrm{CI}[0.10-0.74])$.

Conclusions: The Asp/Gly genotype of the TLR-4 gene was 12.7 times more frequently detected in patients with acute brucellosis with CVS diseases than in healthy individuals and 9.5 times more often than in patients without CVS diseases $(p<0.05)$. The Arg/Gln genotype of the TLR-2 gene was 2.4 times more frequently detected in patients with acute brucellosis with CVS diseases than in healthy individuals $(\mathrm{p}<0.05)$.

Keywords: acute brucellosis, TLR-4, TLR-2, polymorphism, cardiovascular system.

DOI: $10.21303 / 2504-5679.2019 .00923$

\section{Introduction}

Brucellosis is one of the most common zoonotic infections in the world, annually there are about 500 thousand new cases $[1,2]$. Despite the wide spread of this infection in the world, there are areas with a pronounced endemic for brucellosis. These territories include the Republic of Azerbaijan, where new cases of brucellosis are recorded annually [3, 4].

An important social aspect of brucellosis is the high proportion among people with brucellosis - children and adolescents, people of young working age, as well as involvement in the epidemic process of people who are not professionally associated with the source of possible infection $[5,6]$. The disease occurs with the affection of all organs and systems, which leads to the development of extremely adverse effects: loss of working ability and disability of patients, which determines its high socio-economic significance $[7,8]$. According to different data, complications of the cardiovascular system in patients with brucellosis occur in less than $2-10 \%$ of patients. The endocardium is most often affected $[9,10]$.

It is known that the first line of protection of the body against infectious agents, including Brucella, is the innate immunity system [11, 12]. Microbial detection using Toll-like receptors (TLR) is one of the decisive steps in the activation of the innate immune response and is important for the reliable initiation of the adaptive immune response $[13,14]$. Recent studies have shown that both members of the TLR family (TLR2 and TLR4) recognize components of different pathogens. Thus, TLR-2 interacts predominantly with lipoproteins of gram-positive bacteria, whereas TLR-4 interacts with lipopolysaccharide of gram-negative bacteria $[15,16]$.

To date, the study of the polymorphism of the genes of inflammatory regulatory molecules is of particular relevance. Determining their role in the pathogenesis of many diseases, including brucellosis, together with the achievements of modern genomics, allows us to predict the risk of developing the pathology or the severity of its course, on the other hand, to personify pharmacotherapy.

\section{Aim of the research}

Determine the frequency of TLR-2 (Arg753Gln) and TLR-4 (Asp299Gly) polymorphisms in patients with acute brucellosis with cardiovascular lesions in the Republic of Azerbaijan.

\section{Materials and methods}

We examined 178 patients with brucellosis who sought medical care at the Baku Clinic and the Central Clinical Hospital of Baku. All patients gave permission for their inclusion in the study.

The diagnosis of acute brucellosis was established on the basis of clinical data, anamnesis, including epidemiological, objective examination data, results of laboratory diagnostics, including specific ones.

Specific research methods were performed by ELISA on Awareness and Stat Fax 3200 devices using NovaLisa Brusella IgG, IgM test systems (Germany) with the detection of IgM and IgG.

The criteria for inclusion in the study was the diagnosis of acute brucellosis, while taking into account the duration of the clinical symptoms, namely up to 3 months after the first complaints appeared.

According to the criteria for inclusion in the study, out of 178 patients examined, only 120 people fully met all the criteria, which made up the main group. The control group consisted of 30 healthy 
individuals who underwent a scheduled annual inspection. Groups were representative by age and sex. Patients of both groups are ethnic Azerbaijanis who permanently reside in the Republic of Azerbaijan. The average age of patients in the main group was $35.9 \pm 2.8$ years. Male subjects were predominant $-75.00 \%$.

In order to assess the state of the cardiovascular system (CVS), all patients were registered with an electrocardiogram (ECG) according to the standard technique in 12 standard leads. Measurement of blood pressure (BP) was carried out according to the recommendations of WHO experts (2014). To assess the parameters of systemic and intracardiac hemodynamics, ultrasound test (EchoCG) of the heart was used using standard accesses for examination and analysis of the necessary indicators of the structural and functional state of the heart (as recommended by the European Society of Cardiology, 2016).

All patients were determined polymorphism (Arg753Gln) TLR-2. The DNA amplifications of the studied loci were carried out automatically using the following primer structure: F: 5'-GAGTGGTGCAAGTATGAACTGGA-3', R: 5'-TCCCAACTAGACAAAGACTGGTCT-3'. After initial denaturation at $94{ }^{\circ} \mathrm{C}$ for 5 minutes, each stage was carried out in 3 stages: denaturation $94{ }^{\circ} \mathrm{C}(30 \mathrm{~s})$, annealing of primers $(30-45 \mathrm{~s})$, elongation $-72{ }^{\circ} \mathrm{C}(30-40 \mathrm{~s})$. The final elongation lasted 10 minutes at $72{ }^{\circ} \mathrm{C}$. To identify the alleles of the TLR-2 gene, restriction analysis of amplicons was performed using the Pst I restriction endonuclease (NPO 56) and restriction was performed for 12 hours at $37^{\circ} \mathrm{C}$. The products of hydrolysis of the amplified sequences were analyzed by electrophoresis in $2 \%$ agarose gel.

TLR-4 polymorphism (Asp299Gly) was also determined for all patients in both groups. Genomic DNA was isolated from peripheral venous blood, which was collected from the cubital vein into sterile vacutainers with stabilizer 44 (EDTA) using the "DNA / RNA isolation kit from serum or blood plasma” (NPF “LiTech”, Russia). The Asp299Gly polymorphism TLR-4 was amplified by PCR using specific oligonucleotide primers. Amplifications were performed on a Tertsik amplificator (DNATechnology, Moscow). The $25 \mu \mathrm{l}$ PCR mix contained $2.5 \mu \mathrm{l}$ of 10x amplification buffer; $2 \mathrm{mM}$ magnesium chloride; $0.2 \mathrm{mmol}$ of each dNTP; $66 \mathrm{ng}$ specific primers; 2.5 units Act. Taq DNA polymerase (SibEnzyme, Russia); 20-50 ng of genomic DNA. $25 \mu \mathrm{l}$ of mineral oil was layered into tubes. Annealing temperature for determining the Asp299Gly TLR-4 polymorphism site is $58{ }^{\circ} \mathrm{C}$. TLR 4 gene alleles were identified by restriction analysis of amplicons using the restriction endonuclease Bsp19 (SibEnzyme, Russia) at $37{ }^{\circ} \mathrm{C}$. Cleavage products of the polymorphic portion of TLR4 genes were detected by electrophoresis in $3 \%$ agarose gel in 1 x TBE buffer (for 2 hours) at a voltage of $2 \mathrm{~V}$ per $1 \mathrm{~cm}$ of gel). PBR322/ BsuRI was used as a DNA molecular weight marker. Gels were stained with ethidium bromide followed by visualization of the results in UV light.

The significance of differences in the distribution of genotypes in polymorphic loci between groups was checked for compliance with the Hardy-Weinberg equilibrium (http:/gen-exp.ru/ calculator_or.php).

Statistical processing of the research results was performed using the IBM SPSS Statistics program, version 12 (20) (licensed No. 9593869, belongs to the Department of Infectious Diseases with a course of epidemiology at the Vinnytsia National Medical University named after NI Pirogov of the Ministry of Health of Ukraine) using parametric and non-parametric assessment methods obtained results. The calculation of the arithmetic average value (M) and standard error of the indicator (m) was carried out. When assessing quality indicators, the frequency of occurrence (\%) and its standard error ( $\mathrm{m} \%$ ) were calculated.

Comparison of the frequencies of genotypes and alleles was performed by analyzing the contingency tables using Fisher's exact test and $\chi^{2}$ test, depending on the assumptions of the analysis. The risk of developing pathology was assessed by calculating the odds ratio (OR) with the $95 \%$ confidence interval (CI) determined using simple logistic regression.

\section{Results}

The study found that 93 patients $(77.50 \pm 3.13 \%)$ with acute brucellosis had some or other signs of CVS malfunctioning that were identified clinically or as a result of a functional examina- 
tion. Such a number of patients with changes in CVS, in our opinion, may be due not only to the direct action of the infectious agent, but also to the previously existing CVS lesion.

The most frequent clinical manifestations of CVS lesions were: weakening of heart sounds (in $45.83 \pm 3.73 \%$ of patients), hypotension (in $40.83 \pm 3.68 \%$ of people) and non-ischemic cardialgia (in $36.67 \pm 3.61 \%$ of patients).

An analysis of ECG data in 12 derivations found that the overwhelming majority of pathologies concerned automatism disorders (in $67.54 \pm 3.51 \%$ of patients) and ventricular repolarization processes (in $31.65 \pm 3.49 \%$ of people). Moreover, among the disorders of automatism, the tendency to tachycardia dominated, the conduction disturbances were expressed mainly by the slowing down of impulse conduction along the bundle of His, and the excitability disturbances - mainly by the appearance of ventricular extrasystoles.

The data of echocardiographic examination of patients with acute brucellosis were also analyzed. In general, the average indicators of the structure and function of the heart in the group of patients with acute brucellosis, according to EchoCG, did not go beyond the framework of the corresponding generally accepted norms. However, the average values of individual indicators differed significantly from those in the control group. So in patients with acute brucellosis compared with the control group, an increase in heart rate was observed by $11.94 \%(p<0.05)$, while the diastolic blood pressure was $18.77 \%$ lower $(p<0.01)$. The level of systolic pressure in the main group was not significantly different from the control group. Also in patients with brucellosis, significant differences in the size and volume of the left ventricle were found. Diastolic size and volume of the left ventricle in the main group, respectively, by $11.91 \%$ and $8.33 \%$ exceed those in the control group $(\mathrm{p}<0.05)$. The size of the left atrium in the main group is $9.51 \%$ higher than the corresponding figure in the group of practically healthy individuals $(p<0.05)$. It has been established that the state of the systolic and diastolic functions of the left ventricle in patients with acute brucellosis varies significantly. The main indicator of the systolic function of the left ventricle, namely the ejection fraction, is $6.90 \%$ lower in the main group of the study than in the control group $(\mathrm{p}<0.05)$. However, a moderate decrease in left ventricular systolic function was recorded only in 6 patients $(5.51 \%)$.

It was found that the Asp/Gly genotype of the TLR-4 gene was 12.7 times more frequent in patients with acute brucellosis with CVS than in healthy individuals and 9.5 times more often than in patients without CVS $(\mathrm{p}<0,05)$. Whereas, the Asp/Asp genotype was more often detected in healthy individuals. The mutant Gly allele was significantly more often, 5.2 times more common among patients with brucellosis with CVS lesion than among healthy individuals and 6.4 times more often than among patients with brucellosis without CVS lesion $(\mathrm{p}<0.05)$ (Table 1).

\section{Table 1}

The detection rate of polymorphism (Asp299Gly) of the TLR-4 gene in patients with brucellosis with and without CVS lesion

\begin{tabular}{ccccccc}
\hline \multirow{2}{*}{$\begin{array}{c}\text { Genotypes and alleles } \\
\text { TLR-4 (Asp299Gly) }\end{array}$} & $\begin{array}{c}\text { Patients with brucellosis with- } \\
\text { out CVS lesions (n=27) }\end{array}$ & $\begin{array}{c}\text { Patients with brucellosis with } \\
\text { CVS lesions (n=93) }\end{array}$ & \multicolumn{2}{c}{$\begin{array}{c}\text { Healthy persons } \\
(\mathbf{n = 3 0 )}\end{array}$} \\
\cline { 2 - 7 } & Abs. & \% & Abs. & \% & Abs. & \% \\
\hline Genotype Asp/Asp & 4 & $14.8 \pm 6.83^{*}$ & 31 & $33.3 \pm 4.88^{*}$ & 27 & $90.0 \pm 5.48$ \\
Genotype Asp/Gly & 23 & $85.2 \pm 6.84^{*}$ & 59 & $63.5 \pm 4.99^{*}$ & 2 & $6.7 \pm 4.56$ \\
Genotype Gly/Gly & 0 & 0 & 3 & $3.2 \pm 1.83$ & 1 & $3.3 \pm 1.81$ \\
Allele Asp & 31 & $57.4 \pm 9.52$ & 121 & $65.1 \pm 4.94$ & 56 & $93.3 \pm 4.56$ \\
Allele Gly & 23 & $42.6 \pm 9.52^{*}$ & 65 & $34.9 \pm 4.94 *$ & 4 & $6.7 \pm 2.14$
\end{tabular}

Note: $*_{-}-p<0.05$ - between patients with brucellosis with and without CVS diseases, and healthy individuals

It was found that the Arg/Gln genotype of the TLR-2 gene was 2.4 times more frequently detected in patients with acute brucellosis with CVS lesion than in healthy individuals $(\mathrm{p}<0.05)$. 
Whereas, the Arg/Arg genotype was more frequently detected in healthy individuals. The mutant Gln allele, significantly more often, 2.3 times was found among patients with brucellosis with CVS lesion than among healthy individuals $(\mathrm{p}<0.05)$. Significant differences between the frequency of detection of polymorphism (Arg753Gln) of the TLR-2 gene in patients with brucellosis without CVS lesions and practically healthy individuals were not identified (Table 2).

Table 2

The frequency of detection of polymorphism (Arg753Gln) of the TLR-2 gene in patients with brucellosis with and without CVS lesions

\begin{tabular}{ccccccc}
\hline \multirow{2}{*}{$\begin{array}{c}\text { Genotypes and alleles } \\
\text { TLR-2 (Arg753Gln) }\end{array}$} & $\begin{array}{c}\text { Patients with brucellosis with- } \\
\text { out CVS lesions (n=27) }\end{array}$ & $\begin{array}{c}\text { Patients with brucellosis with } \\
\text { CVS lesions (n=93) }\end{array}$ & \multicolumn{2}{c}{$\begin{array}{c}\text { Healthy persons } \\
(\mathbf{n = 3 0})\end{array}$} \\
\cline { 2 - 7 } & Abs. & \% & Abs. & \% & Abs. & \% \\
\hline Genotype Asp/Asp & 20 & $74.1 \pm 8.43$ & 49 & $52.7 \pm 5.18^{*}$ & 24 & $80.0 \pm 7.3$ \\
Genotype Asp/Gly & 4 & $14.8 \pm 6.83$ & 30 & $32.3 \pm 4.85^{*}$ & 4 & $13.3 \pm 6.19$ \\
Genotype Gly/Gly & 3 & $11.1 \pm 6.05$ & 14 & $15.0 \pm 3.7^{*}$ & 2 & $6.7 \pm 2.96$ \\
Allele Asp & 44 & $81.5 \pm 7.47$ & 128 & $68.8 \pm 4.8$ & 52 & $86.7 \pm 6.19$ \\
Allele Gly & 10 & $18.5 \pm 7.47$ & 58 & $31.2 \pm 4.8^{*}$ & 8 & $13.3 \pm 6.19$
\end{tabular}

Note: ${ }^{*}-p<0.05-$ between patients with brucellosis with and without CVS lesions, and healthy individuals

The next step in our study was to establish the risks of brucellosis with CVS lesions, taking into account the carriage of polymorphic variants of the TLR-4 and TLR-2 genes. When studying the features of the distribution of allele frequency in patients with brucellosis, it was found that carriers of the Gly allele of the polymorphic (Asp299Gly) TLR-4 gene have an increased risk of developing brucellosis with CVS lesions (OR=7.52, $95 \%$ CI [2.61-21.67]), then as in the case of carriage of the Asp allele, on the contrary, the risk of developing brucellosis is reduced $(\mathrm{OR}=0.13$, $95 \%$ CI [0.05-0.38]); the model is reliable at $\chi^{2}=17.98, \mathrm{p}<0.0001$ (Table 3).

We found that among carriers of the Asp/Gly genotype, a significantly increased risk of brucellosis with CVS lesions $\left(\chi^{2}=30.19 ; \mathrm{p}<0.0001 ; \mathrm{OR}=24.29 ; 95 \%\right.$ CI [5.45-108.37]) was determined, whereas the carrier state is homozygous the Asp / Asp genotype, in contrast, had a protective effect on the development of brucellosis $(\mathrm{OR}=0.06,95 \% \mathrm{CI}[0.02-0.20])$.

Table 3

Association of alleles and genotypes for polymorphism (Asp299Gly) of the TLR-4 gene with susceptibility to brucellosis with CVS lesions

\begin{tabular}{|c|c|c|c|c|c|c|}
\hline \multirow{2}{*}{ Genotypes and alleles } & \multirow{2}{*}{$\begin{array}{l}\text { Patients with brucel- } \\
\text { losis with CVS lesions } \\
\qquad(\mathrm{n}=93)\end{array}$} & \multirow{2}{*}{$\begin{array}{l}\text { Healthy persons } \\
\qquad(\mathbf{n}=\mathbf{3 0})\end{array}$} & \multirow{2}{*}{$\chi^{2}$} & \multirow{2}{*}{ p } & \multicolumn{2}{|c|}{ OR } \\
\hline & & & & & sign. & $95 \%$ CI \\
\hline Allele Asp & 0.651 & 0.933 & \multirow{2}{*}{17.98} & \multirow{2}{*}{$<0,0001$} & 0.13 & $0.05-0.38$ \\
\hline Allele Gly & 0.349 & 0.067 & & & 7.52 & $2.61-21.67$ \\
\hline Genotype Asp/Asp & 0.333 & 0.900 & & & 0.06 & $0.02-0.20$ \\
\hline Genotype Asp/Gly & 0.634 & 0.067 & 30.19 & $<0,0001$ & 24.29 & $5.45-108.37$ \\
\hline Genotype Gly/Gly & 0.032 & 0.033 & & & 0.97 & $0.10-9.66$ \\
\hline
\end{tabular}

When studying the characteristics of the distribution of allele frequency in patients with brucellosis, it has been found that carriers of the Gln allele of the polymorphic (Arg753Gln) TLR-2 gene have an increased risk of developing brucellosis with CVS (OR=2.95, 95 \% CI [1.31-6.60]), model reliable at $\chi^{2}=7.36, p=0.007$ (Table 4). 
We found that among patients with brucellosis with CVS and practically healthy individuals, the frequency of the heterozygous genotype Arg/Gln (Arg753Gln) of the TLR-2 gene was 0.323 and 0.133 , respectively. That is, among carriers of this genotype, a significantly increased risk of brucellosis with CVS $\left(\chi^{2}=5.68 ; \mathrm{p}=0.02 ; \mathrm{OR}=3.10 ; 95 \%\right.$ CI [0.99-9.67]) was determined, while the homozygous genotype Arg/Arg, on the contrary, it had a protective effect on the development of brucellosis $(\mathrm{OR}=0.28,95 \% \mathrm{CI}[0.10-0.74])$. It was also found that carriers of the mutant homozygous genotype Gln/Gln also had an increased risk of developing acute brucellosis with CVS lesions $\left(\chi^{2}=5.68 ; \mathrm{p}=0.02 ; \mathrm{OR}=2.48 ; 95 \%\right.$ CI [0.53-11.61]).

\section{Table 4}

Association of alleles and genotypes for polymorphism (Arg753Gln) of the TLR-2 gene with susceptibility to brucellosis with CVS lesion

\begin{tabular}{|c|c|c|c|c|c|c|}
\hline \multirow{2}{*}{ Genotypes and alleles } & \multirow{2}{*}{$\begin{array}{l}\text { Patients with brucel- } \\
\text { losis with CVS lesions } \\
\text { (n=93) }\end{array}$} & \multirow{2}{*}{$\begin{array}{l}\text { Healthy persons } \\
\qquad(\mathbf{n = 3 0})\end{array}$} & \multirow{2}{*}{$\chi^{2}$} & \multirow{2}{*}{$\mathbf{p}$} & \multicolumn{2}{|c|}{ OR } \\
\hline & & & & & sign. & $95 \%$ CI \\
\hline Allele Asp & 0.688 & 0.867 & & & 0.34 & $0.15-0.76$ \\
\hline Allele Gly & 0.312 & 0.133 & 1.50 & 0.001 & 2.95 & $1.31-6.60$ \\
\hline Genotype Asp/Asp & 0.527 & 0.800 & & & 0.28 & $0.10-0.74$ \\
\hline Genotype Asp/Gly & 0.323 & 0.133 & 5.68 & 0.02 & 3.10 & $0.99-9.67$ \\
\hline Genotype Gly/Gly & 0.151 & 0.067 & & & 2.48 & $0.53-11.61$ \\
\hline
\end{tabular}

\section{Discussion}

The role of TLR-4 polymorphism and its relationship with brucellosis is an ambiguous and poorly understood problem. At the moment, in the available scientific literature, there are single data, as in one study, the polymorphism (Asp299Gly) of the TLR-4 gene was analyzed in patients with brucellosis. Based on the analysis of which, the researchers concluded that the Gly allele was more common among patients with brucellosis compared with healthy individuals (33.6\% versus $20.7 \%, p=0.000003$ ). That is, this study first revealed the link between the genetic polymorphism of the TLR4 gene and susceptibility to brucellosis [17]. As for the role of TLR-2 polymorphism and its relationship with brucellosis, at the moment there is only data relating to TLR-2 polymorphism and various diseases caused by infectious agents. So, it was found that the TLR2 polymorphism was associated with septic shock [18]. A link was also found with tuberculosis, rheumatic fever [19, 20].

Considering the small number of works devoted to the role of TLR-2 and TLR-4 polymorphism among patients with brucellosis, and especially certain groups with CVS lesions, of the hepatobiliary systems. In our opinion, an important aspect is a more thorough study of the state of the cardiovascular system with the obligatory use of instrumental methods of examination with the aim of early detection of signs of damage, timely involvement of appropriate therapeutic measures, as well as with the study of genetically determined risk factors for the development of these complications among patients with brucellosis.

\section{Conclusions}

1. The most frequent clinical manifestations of CVS lesions were: weakening of heart tones (in $45.83 \pm 3.73 \%$ of patients), hypotension (in $40.83 \pm 3.68 \%$ of people) and non-ischemic cardialgia (in $36.67 \pm 3,61 \%$ of patients).

2. The Asp/Gly genotype of the TLR-4 gene was 12.7 times more frequent in patients with acute brucellosis with CVS lesions than in healthy individuals and 9.5 times more often than in patients without CVS lesions $(\mathrm{p}<0.05)$.

3. The Arg/Gln genotype of the TLR-2 gene was 2.4 times more frequently detected in patients with acute brucellosis with CVS lesions than in healthy individuals $(p<0.05)$. 
4. Among carriers of the Asp/Gly genotype of the TLR-4 gene, an increased risk of brucellosis with CVS lesions $\left(\chi^{2}=30.19 ; \mathrm{p}<0.0001 ; \mathrm{OR}=24.29 ; 95 \%\right.$ CI [5.45-108.37]) was determined, while the carriage the homozygous genotype Asp/Asp, on the contrary, had a protective effect on the development of brucellosis $(\mathrm{OR}=0.06,95 \% \mathrm{CI}[0.02-0.20])$.

5. Among the carriers of the Arg/Gln genotype and the Gln/Gln genotype of the TLR-2 gene, a significantly increased risk of brucellosis with CVS lesions was determined $\left(\chi^{2}=5.68 ; \mathrm{p}=0.02\right.$; $\mathrm{OR}=3.10$; $95 \% \mathrm{CI}[0.99-9.67])$ and $(\mathrm{OR}=2.48$; $95 \% \mathrm{CI}$ [0.53-11.61]), respectively. While the carriage of the homozygous Arg / Arg genotype, on the contrary, had a protective effect on the development of brucellosis (OR=0.28, $95 \%$ CI [0.10-0.74]).

\section{References}

[1] Najafi, N., Davoudi, A., Hassantabar, S. R., Haddadi, R. (2018). Investigating the Epidemiologic, Laboratory, and Clinical Features of Brucellosis Patients Hospitalized in the North of Iran During 2009-2014. Archives of Clinical Infectious Diseases, 13 (2). doi: http://doi.org/10.5812/archcid.61012

[2] Mugahi, S., Nashibi, R., Alavi, S. M., Gharkholu, S., Najafi, K. (2014). Epidemiological Features, Clinical Manifestation and Laboratory Findings of Patients With Brucellosis. Archives of Clinical Infectious Diseases, 9 (1). doi: http://doi.org/10.5812/ archcid. 17270

[3] Nourbakhsh, F., Borooni, S., Barangi, S., Tajbakhsh, E. (2017). Diagnosis of clinical and laboratory findings of brucellosis in Isfahan. International Archives of Health Sciences, 4 (2), 48. doi: http://doi.org/10.4103/iahs.iahs_1_17

[4] Garcell, H. G., Garcia, E. G., Pueyo, P. V., Martín, I. R., Arias, A. V., Alfonso Serrano, R. N. (2016). Outbreaks of brucellosis related to the consumption of unpasteurized camel milk. Journal of Infection and Public Health, 9 (4), 523-527. doi: http:// doi.org/10.1016/j.jiph.2015.12.006

[5] Kazak, E., Akalın, H., Yılmaz, E., Heper, Y., Mıstık, R., Sınırtaş, M. et. al. (2016). Brucellosis: a retrospective evaluation of 164 cases. Singapore Medical Journal, 57 (11), 624-629. doi: http://doi.org/10.11622/smedj.2015163

[6] Bukharie, H. A. (2009). Clinical features, complications and treatment outcome of Brucella infection: Ten years' experience in an endemic area. Tropical Journal of Pharmaceutical Research, 8 (4). doi: http://doi.org/10.4314/tjpr.v8i4.45221

[7] Nassaji, M., Govhary, A., Ghorbani, R. (2015). Epidemiological, clinical and laboratory findings in adult patients with acute brucellosis: A case-control study. Acta Medica Mediterranea, 1319-1325. Available at: http://eprints.semums.ac.ir/id/eprint/78

[8] Sofian, M., Aghakhani, A., Velayati, A. A., Banifazl, M., Eslamifar, A., Ramezani, A. (2008). Risk factors for human brucellosis in Iran: a case-control study. International Journal of Infectious Diseases, 12 (2), 157-161. doi: http://doi.org/10.1016/ j.ijid.2007.04.019

[9] Lagadinou, M., Mplani, V., Velissaris, D., Davlouros, P., Marangos, M. (2019). Myocarditis Caused by Brucella melitensis in the Absence of Endocarditis: Case Report and Review of the Literature. Case Reports in Medicine, 2019, 1-4. doi: http:// doi.org/10.1155/2019/3701016

[10] Pandit, V. R., Seshadri, S., Valsalan, R., Bahuleyan, S., Vandana, K. E., Kori, P. (2010). Acute brucellosis complicated by fatal myocarditis. International Journal of Infectious Diseases, 14 (4), e358-e360. doi: http://doi.org/10.1016/j.ijid.2009.05.013

[11] Yurko, K. V. (2015). Prevalence of TLR-4 gene polymorphism in patients co-infected with HIV/HCV. ScienceRise, 11 (3 (16)), 86-89. doi: http://doi.org/10.15587/2313-8416.2015.54495

[12] Cai, Y., Peng, Y.-H., Tang, Z., Guo, X.-L., Qing, Y.-F., Liang, S.-H. et. al. (2014). Association of Toll-like receptor 2 polymorphisms with gout. Biomedical Reports, 2 (2), 292-296. doi: http://doi.org/10.3892/br.2014.224

[13] Kawai, T., Akira, S. (2010). The role of pattern-recognition receptors in innate immunity: update on Toll-like receptors. Nature Immunology, 11 (5), 373-384. doi: http://doi.org/10.1038/ni.1863

[14] Tongtawee, T., Bartpho, T., Kaewpitoon, S., Kaewpitoon, N., Dechsukhum, C., Leeanansaksiri, W. et. al. (2018). Genetic polymorphisms in TLR1, TLR2, TLR4, and TLR10 of Helicobacter pylori-associated gastritis. European Journal of Cancer Prevention, 27 (2), 118-123. doi: http://doi.org/10.1097/cej.0000000000000347

[15] Ferrero, M. C., Hielpos, M. S., Carvalho, N. B., Barrionuevo, P., Corsetti, P. P., Giambartolomei, G. H. et. al. (2013). Key Role of Toll-Like Receptor 2 in the Inflammatory Response and Major Histocompatibility Complex Class II Downregulation in Brucella abortus-Infected Alveolar Macrophages. Infection and Immunity, 82 (2), 626-639. doi: http://doi.org/10.1128/iai.01237-13

[16] Oliveira, S. C., de Oliveira, F. S., Macedo, G. C., de Almeida, L. A., Carvalho, N. B. (2008). The role of innate immune receptors in the control of Brucella abortus infection: Toll-like receptors and beyond. Microbes and Infection, 10 (9), $1005-1009$. doi: http://doi.org/10.1016/j.micinf.2008.07.005

[17] Rezazadeh, M., Hajilooi, M., Rafiei, A., Haidari, M., Nikoopour, E., Kerammat, F. et. al. (2006). TLR4 polymorphism in Iranian patients with brucellosis. Journal of Infection, 53 (3), 206-210. doi: http://doi.org/10.1016/j.jinf.2005.10.018 
[18] Nguyen, M.-T., Peisl, L., Barletta, F., Luqman, A., Götz, F. (2018). Toll-Like Receptor 2 and Lipoprotein-Like Lipoproteins Enhance Staphylococcus aureus Invasion in Epithelial Cells. Infection and Immunity, 86 (8). doi: http://doi.org/10.1128/ iai.00627-18

[19] Xue, X., Qiu, Y., Jiang, D., Jin, T., Yan, M., Zhu, X., Chu, Y. (2017). The association analysis of TLR2 and TLR4 gene with tuberculosis in the Tibetan Chinese population. Oncotarget, 8 (68). doi: http://doi.org/10.18632/oncotarget.22996

[20] Zhao, J., Shang, H., Cao, X., Huang, Y., Fang, X., Zhang, S. et. al. (2017). Association of polymorphisms in TLR2 and TLR4 with asthma risk. Medicine, 96 (35), e7909. doi: http://doi.org/10.1097/md.0000000000007909

\title{
USE OF PLATELETS RICH PLASMA AS A FACTOR OF THE REDUCTION OF THE RISK OF EARLY POSTOPERATIVE COMPLICATIONS IN PATIENTS WITH POSTOPERATIVE VENTRAL HERNIAS
}

\author{
Dmitry Atanasov \\ Department of Surgery No. 4 with a course of oncology \\ Center for Reconstructive and Restorative Medicine (University Clinic) \\ Odessa National Medical University \\ 2 Valihovsky ave., Odessa, Ukraine, 65082 \\ dmitriyatanasov@gmail.com
}

\begin{abstract}
Non-tensioned allohernioplasty with a polypropylene mesh implant has several disadvantages associated with the local occurrence of non-specific long-lasting inflammatory reactions in response to a foreign body. Excessive exudation in the implantation zone leads to the formation of seromas, requiring puncture aspiration, which significantly increases the treatment time. In the longterm, chronic prolonged inflammatory process leads to the formation of coarse connective tissue, which explains the development of biomechanical complications. Growth factors, introduced by platelet rich plasma (PRP), stimulate the release of regenerative cytokines, reduce local inflammatory manifestations in the integration of homoplastic grafts and reduce the incidence of postoperative complications.

Aim: through the use of plasma enriched with platelets reduce the severity of early postoperative complications in patients with postoperative ventral hernias.

Materials and methods. A clinical study was performed in the surgical department of the center for reconstructive and restorative medicine (university clinic) of the Odessa National Medical University (ONMedU) in the period from 2013 to 2019 : 84 patients were operated because of postoperative ventral hernia. The average age of patients was $60.1 \pm 7.6$ years. The size of hernial defects was on average $8.2 \mathrm{~cm}$. The average BMI was $31.8 \mathrm{~kg} / \mathrm{m}^{2}$. According to indications, patients underwent a standard surgical extent of intervention: hernia repair, allohernioplasty of the anterior abdominal wall with a lightweight $(80 \mathrm{~g} / \mathrm{m} 2)$ polypropylene implant. After the plastics of the main group, a prosthesis implantation zone was infiltrated with activated autologous PRP, which was prepared by double centrifugation, in a volume of $14-38 \mathrm{ml}$. There was a control group in which PRP infiltration was not performed. The cavity above the mesh implant was actively drained by Redon for $2-4$ days. An ultrasound examination was performed and, if necessary, fine needle aspiration of serous fluid over the mesh was done.

Results. The evaluation of the postoperative period (up to 28 days) in patients of both groups. In none of the cases were manifestations of allergic, pyrogenic, local inflammatory or infectious complications. According to the quantitative assessment of early postoperative complications as well as the assessment of the degree of pain syndrome subjectively, according to VAS, the postoperative period in the main and control study groups was almost identical. The need for puncture aspirations and the total volume of discharge was significantly less in the main study group. The dependence of the severity of the effect of the proposed technology on such factors as the size of the hernial defect, the nature of plastics, and body mass index was noted. The greatest efficacy was demon-
\end{abstract}

